\title{
Forging a Sustainable Student Research Initiative
}

\section{Dr. Tom A. Eppes, University of Hartford}

Professor of Electrical \& Computer Engineering Ph.D. Elec. Engr., University of Michigan MSEE, BSEE, Texas A\&M University

\section{Dr. Ivana Milanovic, University of Hartford}

Prof. Milanovic is a full-time faculty member in the Mechanical Engineering Department at the University of Hartford. Her area of expertise is thermo-fluids with research interests in vortical flows, computational fluid dynamics, multiphysics modeling, and collaborative learning strategies. Prof. Milanovic is a contributing author for more than 70 journal publications, NASA reports, conference papers and software releases. Dr. Milanovic is elected member of the Connecticut Academy of Science and Engineering, and her honors include five NASA Faculty Fellowship Awards, The Bent Award for Scholarly Creativity, Award for Innovations in Teaching and Learning, and Outstanding Teacher Award of the University of Hartford. 


\title{
Forging a Sustainable Student Research Initiative
}

\begin{abstract}
Student participation in mentored research improves learning of engineering and scientific concepts, increases interaction with faculty and industry sponsors, and provides opportunities for work in emerging technology areas. Benefits accrue both to students who pursue a research career and to those who enter applied fields by strengthening their ability to propose innovative solutions. Over the past nine years, we have sought to improve student research in a predominantly teaching institution. The two primary challenges were: (1) academic - how to introduce and promote inquiry-based learning given the constraints, and (2) business - how to obtain and sustain funding for student-based research. Further complicating the effort was a lack of experience on the part of most students in identifying an appropriate research question, estimating the scope of the project, writing an acceptable statement of work, completing the project, and delivering results that could be readily disseminated.
\end{abstract}

The undergraduate engineering curriculum at our institution has built-in project-based cornerstone, sophomore, and senior capstone design courses. The master of engineering is a 30 credit course-only program. By leveraging these two curricula, we developed a successful multidisciplinary modeling course where key learning outcomes strengthen student readiness to perform research. This paper describes the evolution of our overall strategy to overcome challenges and put solutions in place. An overview of the course is presented in the context of how the pedagogy of student research has evolved over time. A summary of accomplishments to date and two specific examples of student work are discussed.

\section{Introduction}

The authors' university is a private liberal arts institution with about 600 undergraduate students enrolled in engineering. There are six Bachelor of Science degree programs accredited by the Engineering Accreditation Commission (EAC) of ABET: acoustical engineering \& music, biomedical, civil, computer, electrical and mechanical engineering. These programs, as well as a Masters of Engineering with about 150 students, are administered by 4 departments with a fulltime faculty of 40 .

The University has long embraced student research and promoted it with its Honors program, the annual Undergraduate Research \& Creativity Colloquium and Graduate Research \& Creativity Symposium showcasing outstanding projects, dedicated funding for targeted underrepresented students such as Women's Education \& Leadership Fund (WFund), and a number of faculty rewards and incentives. Within our engineering college, cornerstone, sophomore, and senior capstone design courses are in place. ${ }^{1-2}$ The capstone course has evolved from projects designed by faculty to industry-sponsored projects where companies provide real-world problems, mentoring and financial support. ${ }^{3}$ Consequently, our student resumes feature not only gradepoint averages and graduate record examination scores; they are rich with examples of creative work, participation in Colloquium and professional conferences delivering presentations or papers. A subset of students, stimulated by increasingly competitive searches for internships and a desire to pursue prestigious jobs and graduate fellowships, seeks additional opportunities to 
broaden their knowledge base. Modest college- (Faculty/Student Partnership, \$3,000) and University-wide (WFund, \$2000-10,000) competitive grants support faculty-student research outside the curriculum, while the Connecticut NASA Space Grant consortium provides additional funding opportunities.

This paper describes our efforts to enhance the student research infrastructure within the authors' College. A key component was the development of a multidisciplinary modeling course that integrates four teaching and learning strategies. An inquiry-based learning (IBL) approach supported by scaffolded assignments leads to an independent research project on a relevant topic. The benefits we have observed include the development of modeling skills marketable to external entities facing real-world problems, presentations at the University colloquia and symposia, peer-reviewed conference or journal papers, and application software releases. A number of students have displayed increased confidence to start applying for research grants, pursue advanced graduate studies and/or compete for positions in high technology fields.

\section{Educational Context}

The term undergraduate research frequently implies some original work as a final product ${ }^{4}$ while a broader definition is inclusive of the overall student experience and development. ${ }^{5}$

Considerable differences in perceiving the nature of undergraduate research and its ties with the curriculum stem from developments in the United States (US) higher education throughout the last fifty years. When MIT launched its Undergraduate Research Opportunities Program (UROP) in 1969, the concept of undergraduates working on faculty-mentored effort was novel. ${ }^{6}$ Students could choose either a faculty project or recruit another faculty interested in their idea then receive academic credit for the work carried out. Research teams could apply for out-of-pocket expenses and seed funding, and the UROP stipends were made available during the summer to promote continuing participation. ${ }^{7}$

The Council on Undergraduate Research (CUR), founded in 1978 to support research in chemistry in private liberal arts colleges, has grown to include all disciplines and types of institutions. ${ }^{8}$ While CUR has a motto 'Learning Through Research', it defines undergraduate research as an inquiry or investigation that makes an original intellectual or creative contribution to the discipline. As noted by Jenkins and Healey, ${ }^{5}$ CUR promotes learning through research irrespective of the knowledge type and in parallel emphasizes original contribution.

Education by means of discovery that had been possible in developed society with relatively simple knowledge base began to face challenges in the second half of $20^{\text {th }}$ century. ${ }^{9}$ A shift from elite to universal higher education and knowledge growth have significantly increased the cost of higher education while federal, state, and corporate support has not adequately responded to this worsening condition. The Neal Report ${ }^{10}$ documented a number of quality problems in undergraduate infrastructure, a funding focus on graduate education and research, and a lowlevel of support for initiatives by the National Science Foundation (NSF). In response, the NSF started funding research experiences for undergraduates and created recognition awards for the integration of research and education.

While the Boyer Report ${ }^{11}$ advocated changes in undergraduate education at research-oriented universities, its recommendations to strengthen the research experience have resonated across the 
higher education landscape. A research-based learning standard, an inquiry-based first year curricula, and a culminating capstone experience collectively required a shift in the educational paradigm from teaching to learning and discovery. In the process, IBL was shown to be both an effective form of pedagogy ${ }^{12,13}$ and an important means of connecting research and teaching. ${ }^{14}$

Over the last decade, educational proponents have advocated far-reaching efforts to increase the number and quality of higher education graduates. ${ }^{15}$ In 2005, the Association of American Colleges and Universities (AACU) launched the initiative, Liberal Education and America's Promise (LEAP): Excellence for Everyone as a Nation Goes to College. ${ }^{16}$ LEAP recommends that students acquire four blocks of essential learning abilities. One of them being intellectual and practical skills consisting of: inquiry/analysis, critical and creative thinking, written and oral communication, quantitative reasoning, information literacy, teamwork and problem solving. The influential call for adoption of the Student as Scholar Model ${ }^{17}$ has informed the context of student development and liberal education and thus has provided an integrating framework for highly effective long-term learning. Hodge et al. ${ }^{17}$ built on LEAP by arguing that the model both draws on and adds to the impact of liberal education on student learning.

The undergraduate engineering curriculum at our institution is limited to built-in project-based cornerstone, sophomore, and senior capstone design courses. The master of engineering in the past few years has become mostly a two-year, course-only program. Clearly, there was a need for a broader strategy aimed at improving our student research capabilities by incorporating an embedded IBL component into the curriculum.

\section{Background}

Our focus on multiphysics research began in 2006 when the University received a grant to investigate advanced laser processing as applied to the aerospace manufacturing industry. The grant was sponsored by the Connecticut Center for Advanced Technology (CCAT) under the National Aerospace Leadership Initiative (NALI) over a period of two years. One project focused on percussion laser drilling of jet engine components with the objective of creating an integrated model of the process including all thermal, fluid, optical, electromagnetic, chemical, and kinetic effects. A faculty-student team developed an enabling utility called Drilling Routine for Estimating Analyzing and Modeling (DREAM), a standalone PC application that simplified the steps required to identify the settings needed to produce a desired hole size and shape. The alpha release ${ }^{18}$ was distributed to over 30 scientists and engineers in the aerospace manufacturing industry. Encouraged by the positive user feedback and reception at conferences, ${ }^{19-21}$ a beta release of DREAM ${ }^{22}$ included several enhancements to better optimize the drilling process. ${ }^{23}$

At this point, we combined the idea of improving student research with the development of a course focused on the methods and techniques of multiphysics modeling ${ }^{24}$ with an IBL component. In the process, COMSOL Multiphysics® software was acquired with the aid of an internal grant primarily because it can model and simulate any physics-based system. This choice of simulation tool for use in the classroom has been validated by a number of pedagogical studies. COMSOL-based simulations were used to improve teaching effectiveness by Ngabonziza and Delcham ${ }^{25}$ in thermodynamics, Kwon ${ }^{26}$ in fluid mechanics, Yang et al. ${ }^{27}$ in electrical engineering photonics course, and Clark and DiBiasio ${ }^{28}$ in senior chemical engineering 
laboratory. The common threads are improved teaching effectiveness and enhancement of student learning with other by products such as easy visualization of difficult theoretical concepts, introduction to simulation methodology, and increased satisfaction with the overall experience.

\section{Multidisciplinary Modeling Course}

Our multidisciplinary modeling course, initiated four years ago, consists of three credits and transpires over a 15 week semester. It is open to engineering graduate and undergraduate students with a senior standing. All students, upon entering the course, will have covered the following topics in prior semesters: multivariate differential equations, theory of electrical and electronic circuits, and dynamics. Knowledge of numerical methods is not required; however, many students have taken such a course as part of a minor in mathematics. For most of our students this is the first encounter with numerical simulations since only mechanical engineering majors take a third year computer-aided design and analysis course.

A detailed discussion of the course organization and its content was published in Ref. 24. Here, we present a summary of its key elements. The teaching and learning strategies were developed by the authors who have advanced degrees in the disciplines of electrical engineering, mechanical engineering, and computer science. The course is currently taught by one instructor at a time, but other options are being explored. The course design contains four teaching and learning strategies: (1) cooperative learning in teams, (2) scaffolding of project-based assignments building competency, (3) contextualized weekly projects with a focus on relevant topics, and (4) inquiry-based learning. The simulation assignments are organized into three modules: (1) classical projects with prescribed outcomes, (2) higher level transitional projects, and (3) a design of a model (DoM). This structure builds on existing skills and knowledge, connects them in a logical way and engages students in inquiry and learning.

Module 1 (classical projects) familiarizes students with the process of modeling and the software interface. Following a set of procedures, construct working models, students analyze results and write formal reports. Module 2 (transitional projects) have defined objectives; however, some design elements are intentionally left out prompting students to synthesize a working model so that meaningful results can be acquired. Although the goal is clearly stated, the task of filling in the missing pieces is the challenge. Module 3 (DoM project) is the culminating experience in which students working in teams of two are required to integrate prior skills into an independent research initiative. Each team must propose, plan and execute a design that is relevant to the course topics and suitable in rigor. At an end-of-the semester event, each team delivers a formal oral presentation and a written report. As the semester unfolds, students face rising challenges and gradually perform at more complex levels. This curricular structure also enables students to assume greater responsibility for their learning experiences. ${ }^{29}$

Multidisciplinary experience is gained on all module levels in a number of ways. Students are encountering problems: (1) outside of their major, (2) within the major but with multiple coupled physics, or (3) across disciplines. Modules 1 and 2 are carefully chosen to cover an array of physics, no. of physical dimensions, and study types. For example, mechanical engineering majors are exposed to modeling of electromagnetics or photonics phenomena and electrical 
engineering majors are faced with heat transfer and fluid flow problems. Finally, a student may choose to engage in a DoM that encompasses more than one set of physics equations or requires physics outside of the primary discipline.

\section{Results}

The focus on multidisciplinary modeling has been active for nine years while course been offered since summer 2011 for a total of six times to date with a cumulative completion of 95 out of 96 enrollees. During the course, projects are performed in scaffolded stages with skills and resources introduced in the timely manner. The most challenging component has been the third module in which a majority of students experience difficulties in (1) identifying an area of research interest, (2) synthesizing an appropriate scope of work, (3) incorporating validation by using benchmark experimental data, and (4) providing a final report that is dissemination-ready.

While simulation skills are relatively easily developed, engaging in a topic that is of particular interest and building the knowledge base was challenging. Students have sufficient information on the requirements for the DoM from the beginning of the semester as well as examples of previous studies, but only about $20 \%$ came up with an original research question and adequate background work in time for the proposal presentations. In other words, the majority were treating the DoM as another project with the expectation that the faculty provide a menu of choices, identify resources and supply relevant literature background.

Faced with this issue, we introduced strategies and tools to help students explore potential research topics in a timely manner through log-files and discussions with peers and faculty. Once the question was formulated in the timely manner, students were usually able to identify resources and gather necessary information. In most cases, the proposed scope of work was overly ambitious and did not consider the need to validate the simulation data, and faculty intervention to correct deficiencies was required.

Throughout the semester, we help students develop skills in technical report writing and communicating orally. We emphasize that organizing information into a coherent whole is an essential part of their research. At the end of the semester, students communicate their results in the following forms: (1) abstract, (2) technical report, and (3) oral presentation supported by multi-media materials. A check list and grading criteria were developed that includes all the elements of the DoM.

After completing the course, twenty-one students have demonstrated success in obtaining funding and/or creating formal work products. Table 1 summarizes their accomplishments which consist of a collection of grants/industry stipends, published papers ${ }^{30-39}$, presentations at a University research showcase, and software releases. The most notable results came from students A, B, G, and $\mathrm{H}$ who had multiple work products. The remainder completed research projects and had one to two, typically some type of funding and/or University showcase. Students N, T and U have work in progress so no results are yet available, but are listed to illustrate the pipeline of promising future projects. Since the focus on multidisciplinary modeling began, 14 projects have obtained funding, 12 papers were published, 11 presented at University showcases, and two had software releases. 
Table 1. Student Research Project Accomplishments.

\begin{tabular}{|c|c|c|c|c|c|c|}
\hline \multirow[b]{2}{*}{ STUDENT } & \multicolumn{2}{|c|}{ FUNDING } & \multicolumn{4}{|c|}{ WORK PRODUCTS } \\
\hline & GRANT & INDUSTRY & $\begin{array}{l}\text { JOURNAL } \\
\text { ARTICLE }\end{array}$ & $\begin{array}{c}\text { CONFERENCE } \\
\text { PAPER }\end{array}$ & $\begin{array}{l}\text { UNIVERSITY } \\
\text { SHOWCASE }\end{array}$ & SOFTWARE \\
\hline $\mathrm{A}$ & $\checkmark$ & & & $\checkmark \checkmark$ & $\checkmark$ & $\checkmark$ \\
\hline $\mathrm{B}$ & $\checkmark$ & & & $\checkmark$ & & $\checkmark$ \\
\hline $\mathrm{C}$ & & & $\checkmark$ & $\checkmark$ & & \\
\hline $\mathrm{D}$ & & & & $\checkmark$ & & \\
\hline $\mathrm{E}$ & & & & $\checkmark$ & & \\
\hline $\mathrm{F}$ & & & $\checkmark$ & $\checkmark$ & & \\
\hline G & $\checkmark \checkmark$ & & & & $\checkmark \checkmark \checkmark$ & \\
\hline $\mathrm{H}$ & $\checkmark$ & $\checkmark$ & & & $\checkmark \checkmark$ & \\
\hline I & $\checkmark$ & & $\checkmark$ & & & \\
\hline $\mathrm{J}$ & $\checkmark$ & & & $\checkmark$ & $\checkmark$ & \\
\hline $\mathrm{K}$ & $\checkmark$ & & & & $\checkmark$ & \\
\hline $\mathrm{L}$ & $\checkmark$ & & & & $\checkmark$ & \\
\hline M & & & & $\checkmark$ & & \\
\hline \multicolumn{7}{|l|}{$\mathrm{N}$} \\
\hline $\mathrm{O}$ & & & & & $\checkmark$ & \\
\hline $\mathrm{P}$ & $\checkmark$ & & & & & \\
\hline Q & $\checkmark$ & & & & $\checkmark$ & \\
\hline $\mathrm{R}$ & & $\checkmark$ & & & & \\
\hline $\mathrm{S}$ & & $\checkmark$ & & & & \\
\hline \multicolumn{7}{|l|}{$\mathrm{T}$} \\
\hline \multicolumn{7}{|l|}{$\mathrm{U}$} \\
\hline 21 & 11 & 3 & 3 & 9 & 11 & 3 \\
\hline
\end{tabular}

Table 2 lists the research topics and physics associated with the 21 most successful models to date. Four topics spanned two or more physics representing a more complex undertaking to obtain a solution. The remainder involved a single set of physics; however, these often included complex physical geometries, boundary conditions, or fluid flow regimes. To strengthen the financial incentive and promote greater relevance, our current emphasis is to increase the proportion of industry-sponsored projects. 
Table 2. Modeling Physics by Research Topic.

\begin{tabular}{|c|c|c|c|c|c|c|}
\hline \multirow{2}{*}{$\begin{array}{l}\text { RESEARCH } \\
\text { TOPIC }\end{array}$} & \multirow{2}{*}{$\begin{array}{c}\text { NO. OF } \\
\text { STUDENTS }\end{array}$} & \multicolumn{5}{|c|}{ PHYSICS } \\
\hline & & $\begin{array}{c}\text { HEAT } \\
\text { TRANSFER }\end{array}$ & $\begin{array}{l}\text { FLUID } \\
\text { MECH. }\end{array}$ & $\begin{array}{l}\text { ACOUS. } \\
\text { WAVES }\end{array}$ & $\begin{array}{c}\text { RF } \\
\text { WAVES }\end{array}$ & STRUCTURES \\
\hline $\begin{array}{l}\text { PERCUSSION } \\
\text { LASER DRILLING }\end{array}$ & 4 & $\checkmark$ & $\checkmark$ & & $\checkmark$ & \\
\hline $\begin{array}{l}\text { ELECTRICAL } \\
\text { HEAT SINK DESIGN }\end{array}$ & 4 & $\checkmark$ & $\checkmark$ & & & \\
\hline $\begin{array}{l}\text { PATCH ANTENNA } \\
\text { DESIGN }\end{array}$ & 2 & & & & $\checkmark$ & \\
\hline $\begin{array}{l}\text { DESIGN } \\
\text { OF AN AIRFOIL }\end{array}$ & 3 & & $\checkmark$ & & & \\
\hline $\begin{array}{l}\text { RESONANT MODES } \\
\text { OF AN ACOUSTIC } \\
\text { GUITAR } \\
\end{array}$ & 1 & & & $\checkmark$ & & \\
\hline $\begin{array}{l}\text { SOUND } \\
\text { PROPAGATION } \\
\text { FROM A GONG } \\
\end{array}$ & 1 & & & $\checkmark$ & & $\checkmark$ \\
\hline $\begin{array}{l}\text { IMPINGING JET } \\
\text { MODEL }\end{array}$ & 1 & & $\checkmark$ & & & \\
\hline $\begin{array}{l}\text { OPTICAL FIBER } \\
\text { DRAWING }\end{array}$ & 2 & $\checkmark$ & $\checkmark$ & & & \\
\hline $\begin{array}{l}\text { FLOW OVER A } \\
\text { FORWARD FACING } \\
\text { STEP }\end{array}$ & 1 & & $\checkmark$ & & & \\
\hline
\end{tabular}

To showcase some of our student research, results from two projects are now presented. Student $\mathrm{M}$ had an interest in the area of turbomachinery, more specifically in the secondary flows and cooling of turbine blades. However, this topic greatly exceeded the students' simulation experience and time constraints. Consequently, the faculty mentor suggested a relatively simple geometry of a jet impinging on a wall-mounted cube, shown in Fig. 1, that had both experimental and simulation data available in an open literature. For example, the work of Rundstrom et al. ${ }^{40}$ examined the performance of a cooling technique using an impinging jet in a cross-flow on a heated wall-mounted cube and provided experimental data as well as numerical results. Thus, the investigation of complex vortical flow and its impact on heat transfer was a good match to the student's interest and capability. Figure 2 illustrates the velocity contours predicted by the resulting model. 


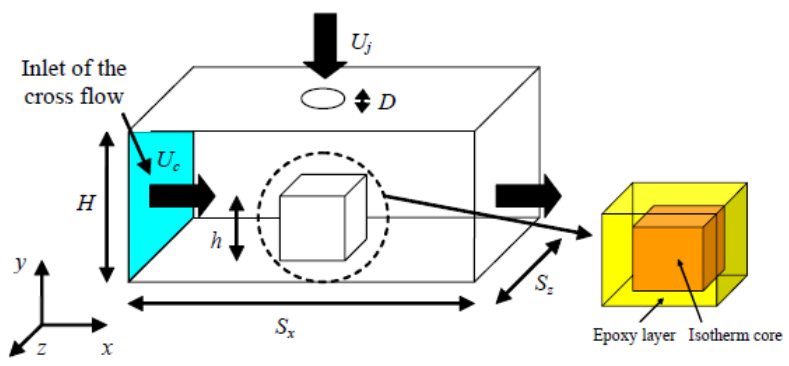

Fig. 1 - Computational domain, Rundstrom et al. ${ }^{40}$

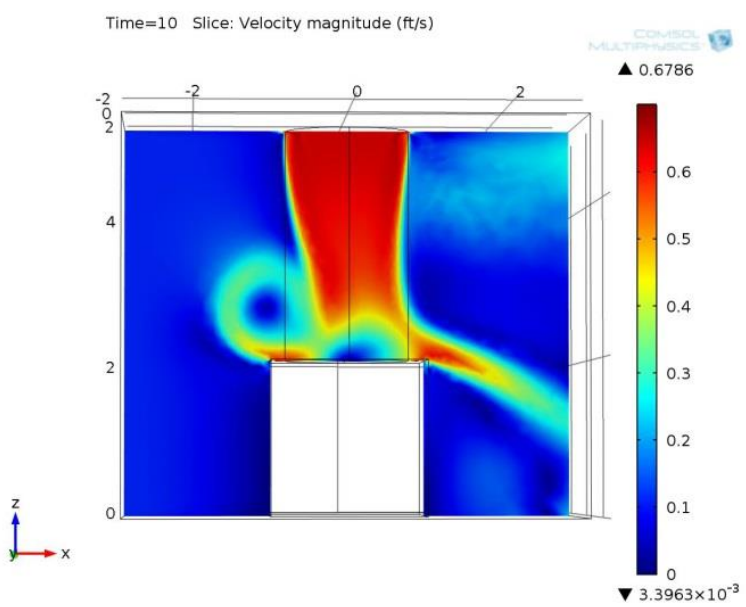

Fig. 2 - Contours of velocity magnitude, student M (2013).

The second project was an industry-sourced and -funded investigation of the optical fiber drawing process. Optical glass fibers are typically fabricated from glass preforms in a vertical drawing process at temperatures near the softening point of the glass. The preform fixing/feeding unit and furnace are shown in Figs. 3-4. A fiber is pulled continuously from the bottom of a vertical drawing tower. The most commonly used electric drawing furnaces are graphite and zirconia-based, i.e. resistive and inductive heating, respectively. Graphite furnaces must be operated under a purge gas atmosphere to prevent oxidation of the graphite heating elements and liners.

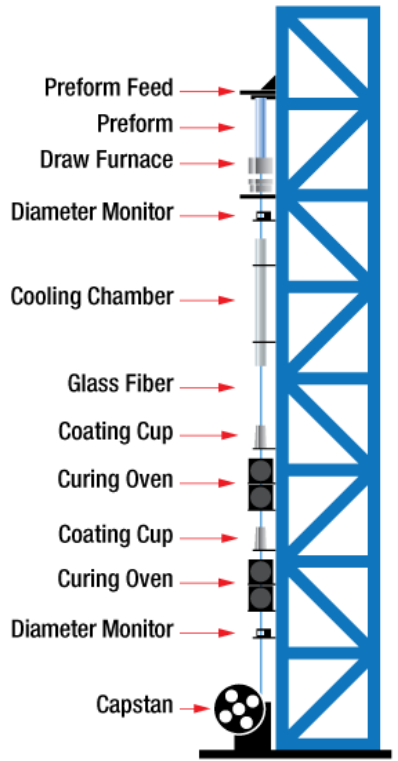

Fig. 3 - Schematic of fiber drawing process, Thorlabs $^{41}$

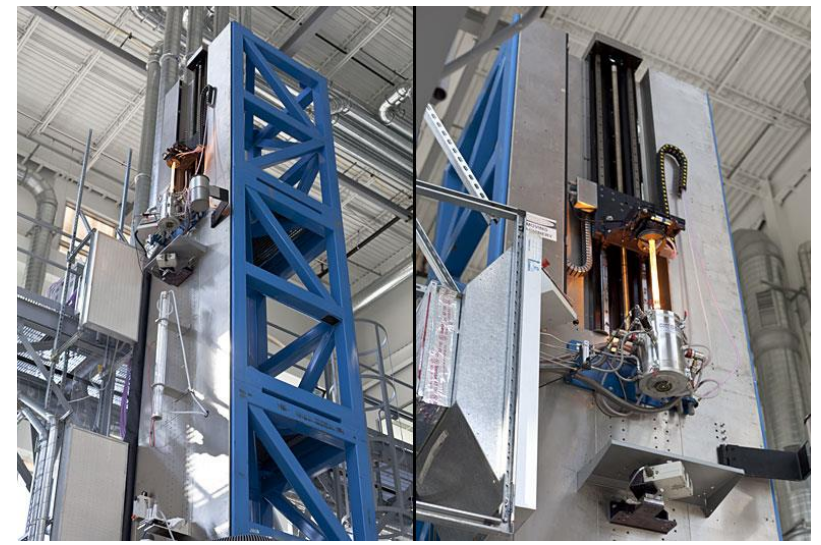

Fig. 4 - Preform being fed into the furnace, Thorlabs $^{41}$

The temperature distribution in the heat zone of the furnace determines the temperature gradient across the preform diameter and thus influences the formation of the neck-down region and the required drawing tension needed to maintain a consistent fiber diameter. Non-contact laser measuring heads monitor the fiber position and diameter after leaving the furnace to enable continuous inline control and adjustment. ${ }^{42}$ 
During the project, two studies were created involving the coupled physics of heat transfer and fluid mechanics. The material properties of the glass included highly nonlinear expressions for dynamic viscosity and thermal conductivity. The first study was a two-dimensional axisymmetric geometry of the drawing furnace. The key outcome was a prediction of the nitrogen purge gas velocity field as illustrated in Fig. 5. The purge gas flows from top to bottom and is a source of convective cooling and viscous drag force in the melt zone. The work showed that the gas flow may have an adverse effect on fiber diameter control although more work is needed to investigate this possibility.

The second study was also a two-dimensional axisymmetric geometry that explored the shape of the neck-down region where melting and re-solidification occurs. In addition to heat transfer and convective cooling, two-phase flow physics was used to predict the glass-nitrogen boundary over time. The shape of the glass is depicted in Fig. 6 as the process advances in time to approach a steady state. This optical fiber drawing project has thus far included contributions from three students.

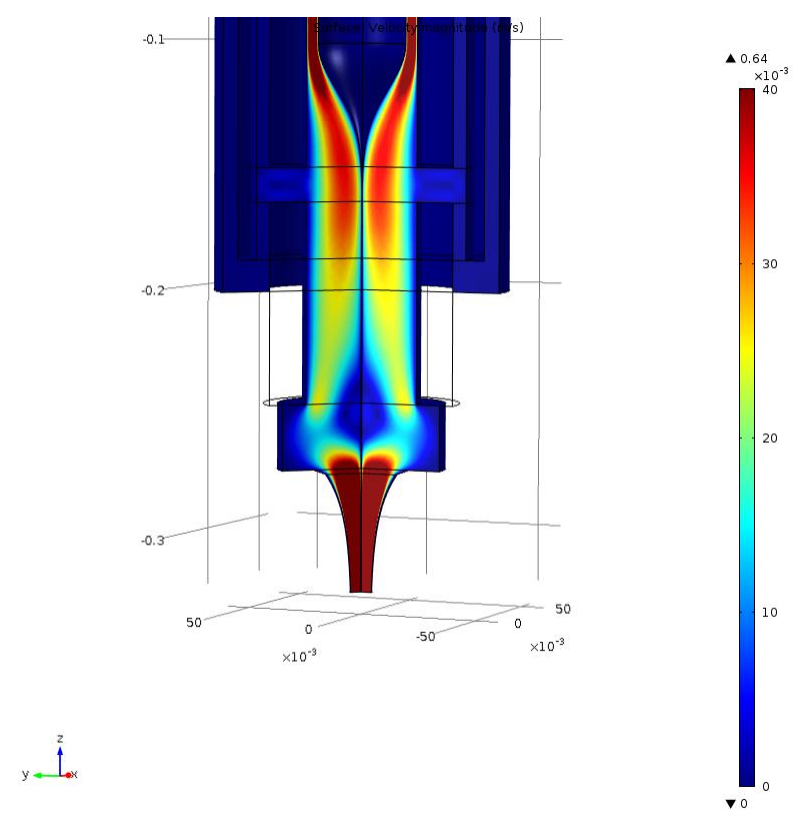

Fig. 5 - Velocity field of nitrogen purge gas.

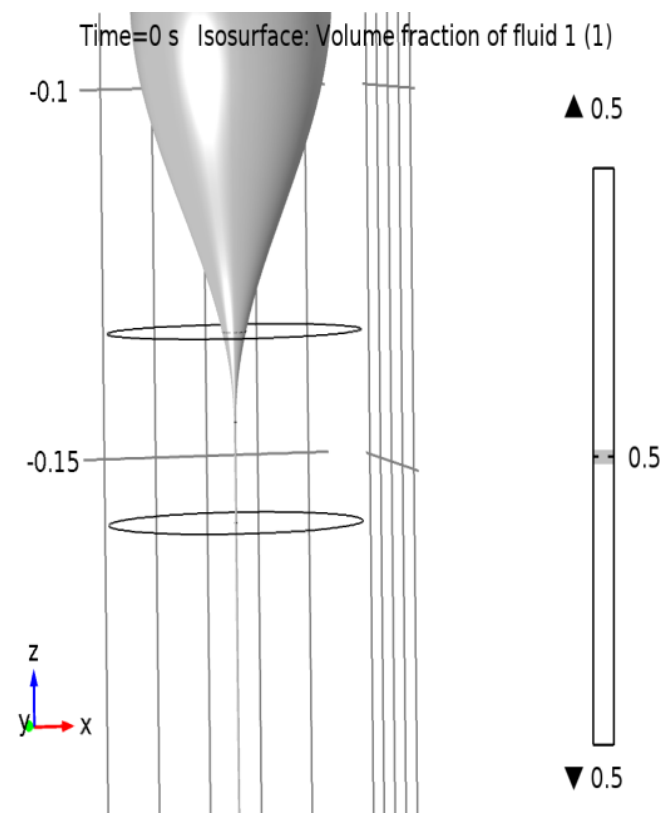

Fig. 6 - Volume fraction of silica glass.

\section{Conclusions}

Our initiative to increase the scope and quality of our graduate and undergraduate research has been successful. The multiphysics modeling course has a $99 \%$ completion rate and contains an IBL component that better equips students with the ability to engage in relevant and advanced topics. After the course, about $20 \%$ of the students have demonstrated one or more of the following accomplishments: securing funding or creating formal work products consisting of published papers, presentations at a University showcase, and/or software releases. 
Two examples, each representing a challenging modeling effort, were presented to show specific results that have been achieved. Continued interest among students in the simulation course and subsequently in pursuing mentored research promises to lead to even more interesting results in the future. Our current strategy is to introduce COMSOL Multiphysics ${ }^{\circledR}$ earlier in the undergraduate curriculum so students who enter the multidisciplinary course will already possess a baseline of skills with the numerical modeling software. Having a larger and better equipped pipeline of students will enable us to grow the proportion of externally-funded work by leveraging a broader cross section of industry contacts.

\section{Bibliography}

1. Shetty, D., Leone, D., Alnajjar, H., Keshawarz, S., Nagurney, L., and Smith L. T. (2001) Integrating Engineering Design with Humanities, Sciences \& Social Sciences Using Integrative Learning Blocks, Proceedings of ASEE Annual Conference. Paper ASEE-2001. Albuquerque, AK.

2. Shetty, D. and Sahay, C. (2003) Innovative Integrated Mechanical Engineering Curriculum, ASME Curriculum Innovation Award Honorable Mention.

3. Eppes, T. A., \& Milanovic, I. (2011) Capstone Design Project Course Pathways. Am. J. Eng. Educ., 2(1), 3542.

4. Kinkead, J. (2003) Learning Through Inquiry: An Overview of Undergraduate Research, New Directions for Teaching and Learning, 93, 5-18.

5. Healey, M. and Jenkins, A. (2009) Developing Undergraduate Research and Inquiry. Research report to the Higher Education Academy. Available from: https://www.heacademy.ac.uk/node/3146 [last accessed Jan 06 2015].

6. McCluskey, E. (2009) Undergraduate Research Opportunities Program marks $40^{\text {th }}$ year. Available from: http://www.technologyreview.com/article/414003/the-soul-of-mit/ [last accessed Jan 06 2015].

7. Cohen, S.A. and McVicar, M.L.A. (1976) Establishing an undergraduate research programme in physics: how it was done. American Journal of Physics. 44 (3), 199-203.

8. Council on Undergraduate Research (CUR) (n.d.) Definition of undergraduate research. Available from: http://www.cur.org/about_cur/fact_sheet/ [last accessed Jan 06 2015].

9. Clark, B. R. (1997). The modern integration of research activities with teaching and learning. Journal of Higher Education, 68(3), 242-255.

10. National Science Board, Task Committee on Undergraduate Science and Engineering Education, H. A. Neal (chair). Undergraduate Science, Mathematics and Engineering Education; Role for the National Science Foundation and Recommendations for Action by Other Sectors to Strengthen Collegiate Education and Pursue Excellence in the Next Generation of US Leadership in Science and Technology. National Science Foundation publication no. NSB 86-100. Washington, DC: National Science Foundation, 1986.

11. Boyer Commission on Educating Undergraduates in the Research University, S. S. Kenny(chair). Reinventing Undergraduate Education: A Blueprint for America's Research Universities. State University of New YorkStony Brook, 1998. 
12. Justice, C., Rice, J., Roy, D., Hudspith, B., Jenkins, H. (2009) Inquiry-based learning in higher education: administrators' perspectives on integrating inquiry pedagogy into the curriculum. High Educ 58, 841-855.

13. Justice, C., Rice, J., Warry, W., Inglis, S., Miller, S. and Sammon S. (2007) Inquiry in higher education: reflections and directions on course design and teaching methods. Innovative Higher Education. 31 (4), 201-14.

14. Healey, M. (2005). Linking research and teaching exploring disciplinary spaces and the role of inquiry-based learning, in Barnett, R. (ed). Reshaping the university: new relationships between research, scholarship and teaching, 30-42. Maidenhead: McGraw-Hill/Open University Press.

15. Eppes, T. A., Milanovic, I., \& Sweitzer. F. (2012). Towards Liberal Education Assessment in Engineering and Technology. J. Coll. Teach. Learn., 9 (3).

16. Association of American Colleges and Universities. (2005). Liberal Education and America's Promise (LEAP): Excellence for Everyone as a Nation Goes to College. Washington, DC.

17. Hodge, D, Pasquesi, K, and Hirsh, M (2007) From Convocation to Capstone: Developing the Student as Scholar, Keynote address, Association of American Colleges and Universities Network for Academic Renewal Conference, April 19-21, Long Beach, California. Available from:

http://www.miami.muohio.edu/president/reports_and_speeches/pdfs/From_Convocation_to_Capstone.pdf [last accessed Jan 09 2015].

18. Eppes, T. A., Milanovic, I. M., Shetty, D., \& Bornas, J. (2007). Alpha release of DREAM software. CCAT Laser Applications Grant, Co-developed a computer utility for estimating, analyzing and modeling percussion laser drilling of aerospace alloys.

19. Eppes, T. A., Milanovic, I. M., Shetty, D., \& Bornas, J. (2006). Drilling Routine for Estimating, Analyzing and Modeling of Laser Processing. Proceedings of 25th International Congress on Applications of Lasers and Electro-Optics (ICALEO). Paper ICALEO-2006-309.

20. Eppes, T. A., Milanovic, I. M., Shetty, D., \& Bornas, J. (2007). Enhanced Percussion Laser Drilling Modeling Utility. Proceedings of 26th International Congress on Applications of Lasers and Electro-Optics (ICALEO). Paper ICALEO-2007-1204.

21. Eppes, T. A., Milanovic, I. M., Shetty, D., \& Bouffard A. (2008). Modeling Utility for Percussion Laser Drilling - Experiment vs. Theory. Proceedings of 3rd Pacific International Conference on Applications of Lasers and Optics (PICALO), 357-362.

22. Eppes, T. A., Milanovic, I. M., Shetty, D., \& Bouffard, A. (2008). Beta release of DREAM software. CCAT Laser Applications Grant, Co-developed an enhanced version of the computer utility described below for estimating, analyzing and modeling percussion laser drilling of aerospace alloys.

23. Eppes, T. A., Milanovic, I. M., \& Shetty, D. (2009). Laser Percussion Drilling Modeling Utility. J. Laser Appl., 21(2): 102-109.

24. Milanovic, I., Eppes, T. A., \& Russell, I. (2011). Engineering Multiphysics Research. Int. J. Online Eng., 7(2), 24-28.

25. Ngabonziza, Y., and Delcham, H. (2014). The Enhancement of Students Learning Through COMSOL Simulation Projects. Proceedings of 2014 ASEE Zone 1. Proceedings of 2014 ASEE Zone 1.

26. Kwon, H. J. (2012). Use of COMSOL Simulation for Undergraduate Fluid Dynamics Course. Proceedings of 2012 ASEE Conference. Paper AC 2012-4407.

27. Yang, B., Huang, Y., Adams, R., Zhang, J., and Burbank, K. (2008). Effective Teaching of Photonics E\&M Theory using COMSOL. Proceedings of 2008 ASEE Conference. Paper AC 2008-1093. 
28. Clark, W, and DiBiasio, D. (2007). Computer Simulation of Laboratory Experiments for Enhanced Learning. Proceedings of 2007 ASEE Conference. Paper AC 2007-823.

29. Eppes, T. A., Milanovic, I., \& Sweitzer, F. (2012). Strengthening Capstone Skills in STEM Programs. Innovat. High. Educ., 37(1), 3-10.

30. Eppes, T. A., Milanovic, I., \& Quarshie, G. (2011). Power Transistor Heat Sink Design Trade-Offs. Proceedings of COMSOL Annual Conference. Boston, MA.

31. Eppes, T., Milanovic, I. \& Thiruvengadam, S. (2011). Patch Antenna Model for Unmanned Aerial Vehicle. Proceedings of COMSOL Annual Conference. Boston, MA.

32. [Invited] Eppes, T. A., Milanovic, I., Shetty, D., \& Daly, J. (2012). Characterization of an Unmanned Aerial Vehicle Wing Design. In M. Kshirsagar, B. Patil, U. Gawande, L. Manzione, D. Shetty, \& T. Eppes (Eds.), Proceedings of International Conference on Innovation and Trends in Applied Computing. (pp. 3-6).Nagpur, Maharashtra, India.

33. Eppes, T. A., Milanovic, I. \& DiPanfilo, M., (2012), 'Resonance Modes in an Acoustic Guitar,' Proceedings of Euro-Amer. Conf. J. Arts \& Sci., Aix en Provence, FR.

34. Eppes, T. A., Milanovic, I., \& Patllola, H. (2012). Early Stage Melt Ejection in Percussion Laser Drilling, Proceedings of COMSOL Annual Conference. Boston, MA.

35. Eppes, T. A., Milanovic, I., \& Quarshie, G. (2012). Finite Element Modeling of a Transistor Heat Sink. Am. J. Eng. Tech. Research. 12 (1): 69-77.

36. Eppes, T. A., Milanovic, I., \& DiPanfilo, M. (2012). Resonance Modes in an Acoustic Guitar. Academic J. Sci., 1 (2).

37. Eppes, T. A., Milanovic, I., and Malik S. (2013). Vibrational Response of a Gong, Proceedings of Euro-Amer. Conf. J. Arts \& Sci.

38. Eppes, T. A., Milanovic, I., \& Malik, S. (2013). Vibrational Response of a Gong. Int. J. Arts Sci., 6 (3), 199212

39. Eppes, T. A., Milanovic, I., and DiPanfilo, M. (2014). Coil-based Microphone Modeling and Analysis, (2014). Microphone, Proceedings of Euro-Amer. Conf. J. Arts \& Sci.

40. Rundstrom, D., Moshfegh, B., and Ooi, A. (2007). RSM and $v^{2}$-f Predictions of an Impinging Jet in a Cross Flow on a Heated Surface and on a Pedestal. Proceedings of $16^{\text {th }}$ Australasian Fluid Mechanics Conference, 316-323.

41. ThorLabs, Specialty Optical Fiber Manufacturing, Available from: http://www.thorlabs.com/newgrouppage9.cfm?objectgroup id=6832\#ad-image-0 [last accessed Jan 242015 ].

42. Schuster, K., Unger, S., Aichele, C., Lindern, F., Grimm, S., Litzkendorf, D., Kobelke, J., Bierlich, J., Wonderaczek, K., Bartlet, H. (2014). Material and technology trends in fiber optics. Adv. Opt. Techn. 3(4): 447-468. 